\title{
Popliteal Angle Measurement
}

National Cancer Institute

\section{Source}

National Cancer Institute. Popliteal Angle Measurement. NCI Thesaurus. Code C89519.

An examination whereby the patient is placed supine, the hip is flexed 90 degrees, and the knee is extended until firm resistance is met. The popliteal angle is the angle from the tibia to the femur. This measurement is used to assess hamstring contracture in children with cerebral palsy. 